\title{
High-Intensity Focused Ultrasound (HIFU) For the Prostate Cancer: 5-year Experience
}

\author{
Vyaches lav Solovov", Leonid Shaplygin, Mikhail Vozdvizhenskiy, Ravil Khametov \\ Department of Interventional Radiology, Samara Regional Oncology Center, Samara, 443031, Russia
}

\begin{abstract}
HIFU shows a success ful treat ment for localized prostate cancer. Here we exp lored the effectiveness of the HIFU treatment for the prostate cancer, hormone-resistant prostate cancer and failu re after external beam rad iotherapy and radical prostatectomy. 795 patients were treated in our centre in 2007 - 2012: Kap lan-Meir analyses of the total group indicated that the risk of progression was $23 \%$ after 5 years of follow-up. Our experience shows that HIFU ablation is safe, minimally invasive, effective treat ment with moderate side effects for the PC, hormone-resistant prostate cancer, HIFU also may be used as a salvage therapy.
\end{abstract}

Keywo rds HIFU, High Intensity Focused Ultrasound, Prostate Cancer

\section{Introduction}

Prostate cancer (PC) in developed countries is the most common malignancy among men and the second leading cause of cancer death after lung cancer[1]. In 2010, PC took the third place in the structure of cancer among male population of Russia (11.0\%) - showed 26,268 new cases of the disease[2]. Over the last 10 years the increase was $155,3 \%$. 10,251 patients died from prostate cancer in 2010 (fourth place on the men's deaths from cancer). Radical prostatectomy (RPE) and external beam radiation therapy (EBRT) are the standard treatments for patients with localized prostate cancer with a life expectancy of at least 10 years[3]. Patients presenting with localized prostate cancer are treated with cu rative intent by surgery or rad iation, but up to $30 \%$ will relapse. Treatment then involves androgenablation therapies and all patients will eventually develop hormone-resistant prostate cancer (HRPC). In the past, systemic treatments for HRPC, such as second line hormone therapy, chemotherapy, mitoxantrone and prednisone, offered palliative benefit, but no survival advantage[4]. Newer treat ments with docetaxel and prednis one have shown to offer both palliative and survival benefits $[5,6]$.

During the last decade new min imally invasive therapeutic modalities for prostate cancer have developed, such as brachytherapy, HIFU and cryotherapy. HIFU is an alternative choice in localized and low or intermediate- risk prostate cancer treatment[7].

Rising PSA in nonmetastatic prostate cancer indicates

* Corresponding author:

samarasdc@yahoo.com (Vyacheslav Solovov)

Published online at http///journal.sapub.org/ijtt

Copyright (C) 2012 Scientific \& Academic Publishing. All Rights Reserved failure of initial local therapy and the onset of early HRPC cancer prior to documented clinical metastases. The ideal salvage therapy for these patients is not clear and includes salvage local therapies and systemic approaches, of which the mainstay is hormonal therapy. Treatment needs to be individualized, based upon the patient's risk of progression, the likelihood of success and the risks involved with the therapy. Therefore attention of scientists is focused on the developed and implemented into clinical practice new effective, minimally invasive treatments for prostate cancer, HRPC and failure after EBRT and RPE[6]. Ho wever, due to the fact that studies analysing the effectiveness of HIFU-therapy for prostate cancer HRPC and failure after EBRT and RPE with a cohort of sufficient size and statistical power is few, the real work done. The main aim of this study is to evaluate the results of HIFU treatment of PC with low and high risk progression, and local recurrence after EBRT and RPE.

\section{Main principles of HIFU}

The first therapeutic trial of high intensity ultrasound beams was carried out in 1942[8]. The Fry brothers were credited with the first application of HIFU for neurologic disorders in humans [9]. High-energy ultrasound, parabolic focused on tissue leads to mechanical alteration of the cells and causes changes in biological structures (Figure 1). During application of focused ultrasound three different physical mechanisms can be observed: mechanical, thermal and cavitation effects[10].

Mechanical effects are induced by sudden pressure increase within the tissue by the HIFU beam being highly energetic. 


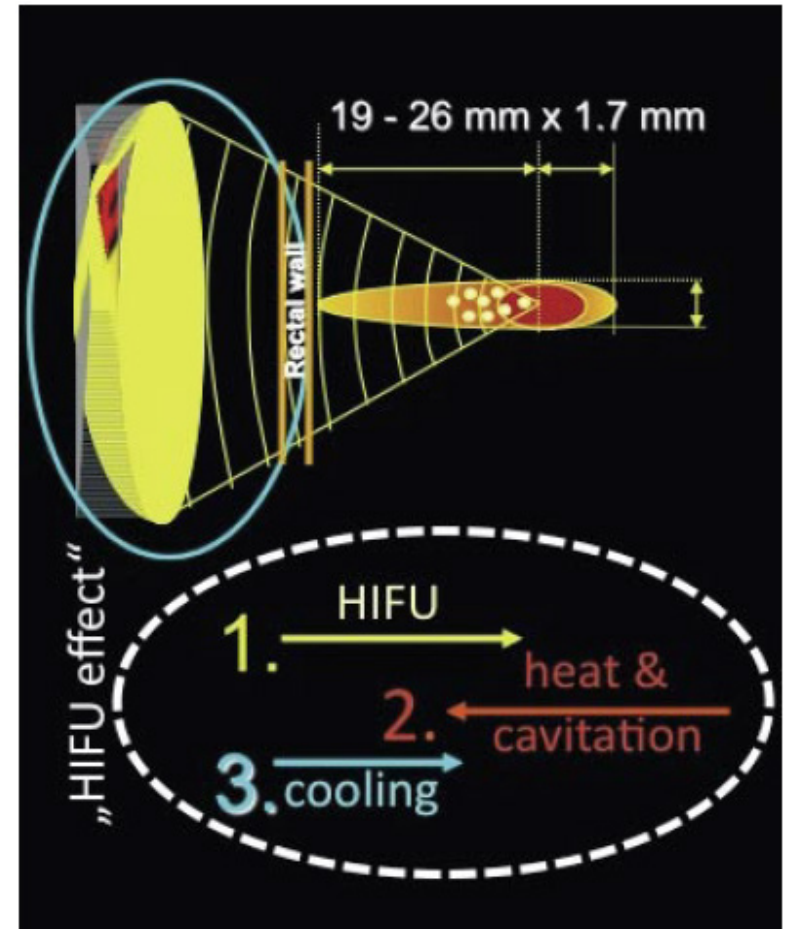

Figure 1. Physical principle of focused energy application

This energy input into the tissue induces formation of cavitation bubbles within the tissue. This mechanical cavitation effect damages cell membranes. A thermal effect is caused by the absorption of ultrasonic energy within the tissue. The temperature increase in tissues depends on the absorption coefficient of the tissue, and the size, shape and temperature sensitivity of the heated area. Biological changes caused by the heating depend on the temperature level and duration of exposure. A "thermal dose", which exceeds a certain threshold, causes tissue coagulation and leads to irreversible tissue damage[11]. High intensive focused ultrasound generates a very high intensity in the focal area, causes high temperatures within a few seconds (up to $85^{\circ} \mathrm{C}$ ) and destroys the tissue in a circumscribed area while surrounding areas remain unharmed. The defined small tissue volume which is destroyed by one single ultrasonic beam is a "primary" lesion. In order to coagulate larger areas, multiple lesions have to be added in a certain algorith $\mathrm{m}$. This can be achieved by mechanically moving the energy source or electronically with a "phased array"[12-16].

HIFU's most important parameters are: 1) the Ultrasound frequency $(\mathrm{MHz}), 2)$ the acoustic intensity (Watts), 3) the duration of application (shot-time), 4) the intervals of the pulses (delay-time), 5) the lateral distance between elementary lesions as well as 6) the longitudinal displacement of the energy source when applying multiple lesions and 7) the penetration depth (focal point) dependent on the applicator design.

These multiple technical parameters are essential in the assembly of a HIFU system for specific tissue and a dedicated application. The most difficult technical decisions concern the selection and design of the piezoelectric energy applicator, the parameters of ultrasound treatment $(\mathrm{MHz}$, Watts), the application algorithm (impulse-delay relation), the imaging system, the intraoperative target and safety features, target localization during treatment (TRUS or MRI) and controls.

The therapeutic ultrasonic energy transducer is characterized mainly by the operating frequency, and the geometric and physical design.

Piezoelectric systems can be operated with sufficient energy density, reproducibility and long-term stability in accordance with the requirements of the therapy which allow the production of geometric shapes in order to adapt them to the different anatomical needs[13]. Current standard urological applications use HIFU transducers with a fixed but adjustable focal point to be moved mechanically (Figure $2 \mathrm{~A}, 2 \mathrm{~B})$.
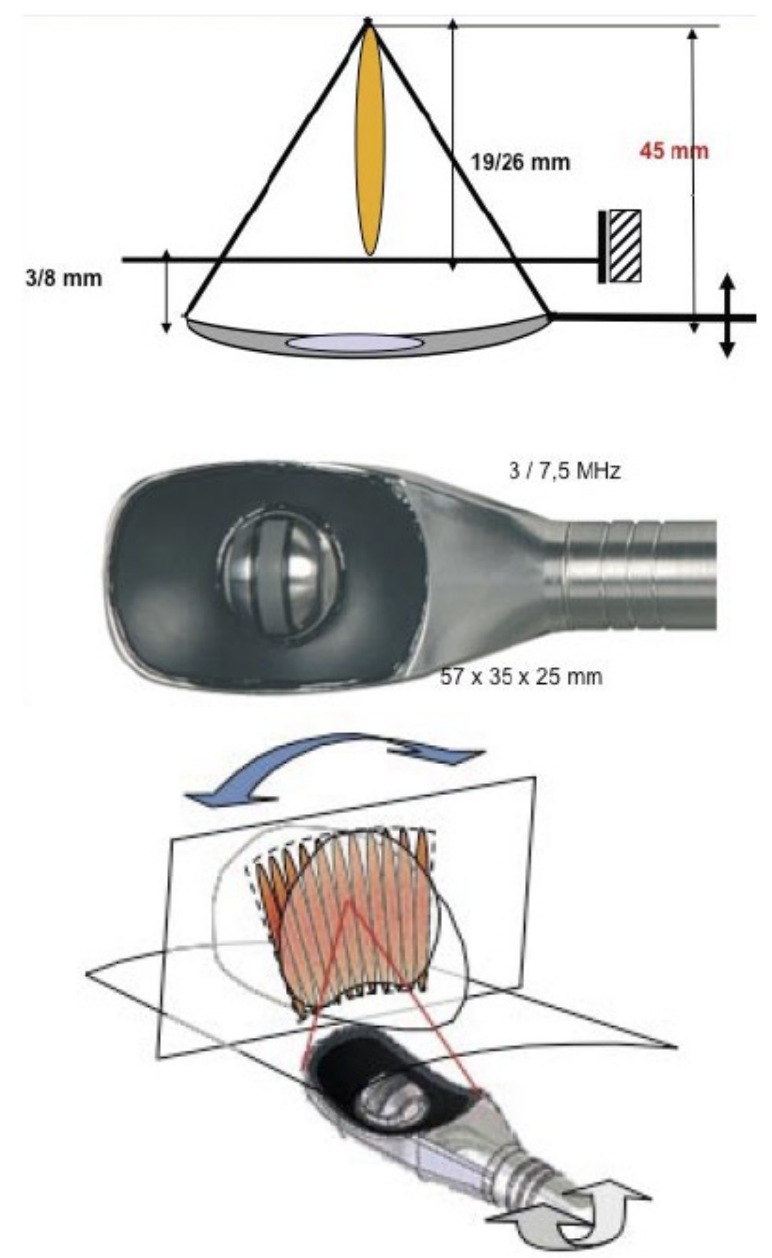

Figure 2. Focal point adjustment: A) Penetration depth (19-26 mm; B) Latero-longitudinally (1.7 mm steps)

To find the ultrasound parameters that are required for the treatment of prostatic tissue, in vitro and in vivo experiments have been performed, as well as computer simulations[17, 18]. MRI is one technique to assess the effectiveness of HIFU treatment and the only one to perform real-time temperature measurements. MRI is used in extracorporeal HIFU treatments for localization and monitoring effectiveness[19,20] and allows for the measurement of 
temperature changes during HIFU treatment[19]. HIFU-induced lesions are temporarily seen as hyper dense areas in diagnostic ultrasound[21]. However, the real extent of a primary lesion cannot be defined precisely because effects such as HIFU reflection (prostatic capsule, calcifications, catheters) absorption (untreated or pretreated tis sue) and cooling (blood ves sels, intrapros tatic TUR cavitiy liquid) are individually different. Further characterization techniques based on ultrasound, contrast-enhanced Doppler[22] or different techniques to the acoustic behavior of tissues have been proposed to determine the extent of HIFU-induced lesions[23]. During a 15-year clinical experience with HIFU in prostate cancer, it has been proven that transrectal ultrasound is safe for reproducible application even without "real time" temperature measurement. A "real time" technology compensating the above mentioned individual tissue effects would be favorable and would optimize tis sue ablation efficacy.

During the last decades transrectal HIFU for prostate cancer has found its way into routine clinical practice with approximately over 30,000 patients having been treated worldwide. Efficacy and side effects of Ablatherm ${ }^{2}$ (EDAP TMS SA, Vaulx-en-Velin, France) (Figure 3) in prostate cancer have been studied as well in a European multicenter study as in other prospective studies and described in detail[24,25]. The authors reported separately about their experiences in well-defined patient groups and established on the basis of these results - standardized procedures and protocols for patient management. For device there is no FDA approval until now, because of ongoing prospective HIFU trials in US.

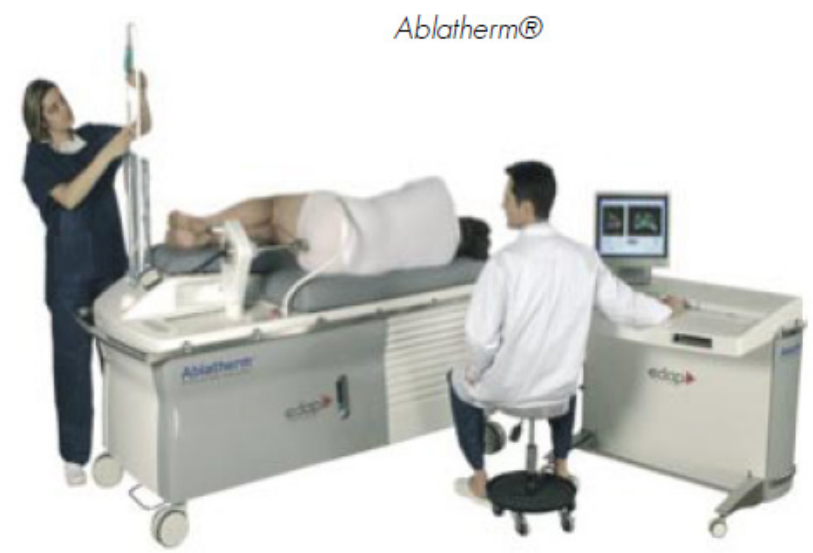

Figure 3. HIFU devices: Ablatherm ${ }^{\circledR}$

In the beginning the only indication for HIFU were patients with localized prostate cancer who were not candidates for surgery due to their age, general health status, co-morbidity or patients who decided against radical prostatectomy.

However, the indications have been expanded based on clinical experience to: partial and focal therapy in unilateral low volume, low Gleason tumors, to incidental prostate cancer after TUR, as salvage therapy in recurrent prostate cancer after radical prostatectomy, rad iotherapy, or hormone ablation, for locally advanced prostate cancer as adjuvant local tumor debulking therapy, for non metastatic as well as metastatic stages and for hormonal resistant prostate cancer (HRPCa). It is well accepted that - besides with TURP - the gland can also be downsized by $30 \%$ within 3 months of androgen depreviation therapy (ADT). Still remaining contraindications for HIFU device are a missing or a small rectum and a damaged rectal wall, caused by previous prostatic/rectal therapies.

Use of TURP prior to HIFU allows the instant removal of any reflecting/deviating calcifications, abscesses, intravesical middle lobes and large ( $>40 \mathrm{ml}$ ) adenomas. The generation of a cavity and its subsequent compression by the rectal balloon increases the accessibility of the HIFU waves to the remaining gland, fixes the residual prostate behind the symphysis and avoids movement artefacts. The beneficial effect in regard to higher effectiveness and lower side effects could be proven in different studies. Furthermore, it expanded the indication range for HIFU to the extent that a larger gland $(>40 \mathrm{ml})$ is no longer regarded as a contraindication.

\section{Materials and Methods}

Seven hundred ninety five patients with PC underwent HIFU in the period between September 2007 and August 2012. Every patient was availab le for oncological follow-up. Inclusion criteria were: patients with prostate localized and locally advanced PC, patients after EBRT or RPE failure. Exclusion criteria were: anal stenosis, metastatic PC. The oncology follow-up consisted of PSA evaluation, MRI and transrectal biopsy in the case of rising PSA. 139 patients were hormone-resistance (median time before hormoneresistance 25 months), 297 - received neoadjuvant hormone therapy 6 months, 320 - no treat ment before HIFU, 39-after the EBRT and RPE failure. 706 patients underwent trans-urethral resection of prostate (TURP) and HIFU-procedure; 89 underwent only HIFU ablation (prostate volume $<40 \mathrm{cc}$ ). All patients underwent spinal anaesthesia. We used the Ablatherm ${ }^{\circledR}$ device (EDAP, Lyon, France).

\section{Results}

In this paper, we analyse our 5 year experience with HIFU treatment of 795 patients with PC. The patients were divided into three groups according to the cancer progression risk: low risk group - 465 patients, Gleas on $\leq 7$, stage T1-2N0M0, age 69 (60-89) years PSA before treatment 40,0 (5,8-92,9) $\mathrm{ng} / \mathrm{ml}$, mean prostate volume - 39,3 (28-92) cc; high risk progression group - 291 patients, Gleason $\leq 9$, stage T2-3N0M0, age 72 (52-83) years, PSA before treatment 30,3 (20,1-60) $\mathrm{ng} / \mathrm{ml}$, mean prostate volume - 41,2 ( 25-198) cc, the third group - patients after EBRT and RPE failure - 39 patients. 
Cancer clinical staging in the whole group was T1 in 149 patients, T2 in 321 patients and T3 in 325 patients. Histological Gleason score was 2 in 42 patients, 3 in 87 patients, 4 in 113 patients, 5 in 136 patient, 6 in 189 patients, 7 in 158 patients, and 8 in 62 patients, 9 in 8 patients.

The average volume of treated prostate tissue was $30 \mathrm{cc}$ (range 5-38.4). High-intensity focused ultrasound treatment had a mean duration of 120 minutes (range 60-245).

The average hospital stay was 7 days. 251 patients underwent TURP+HIFU in the same session. 455 patients with prostate volume larger than $60 \mathrm{cc}$. first underwent TURP and then HIFU after one month. 89 patients with small prostate volume underwent only HIFU. At the end of the procedure a Foley catheter was placed.

Table 1. Groups of patients

\begin{tabular}{|c|c|c|c|c|}
\hline $\begin{array}{c}\text { Group } \\
\text { description }\end{array}$ & $\begin{array}{c}\text { Number of } \\
\text { patients }\end{array}$ & $\begin{array}{c}\text { Age (mean } \\
\text { value) }\end{array}$ & $\begin{array}{c}\text { Prostate } \\
\text { volume, cc }\end{array}$ & $\begin{array}{c}\text { PSA before } \\
\text { treatment, } \\
\mathrm{ng} / \mathrm{mL}\end{array}$ \\
\hline $\begin{array}{c}\text { Gleason } \\
\text { score } \leq 7, \\
\text { stage } \\
\text { T1-2N0M0 }\end{array}$ & 465 & 69 & $\begin{array}{c}39,3 \\
(28-92)\end{array}$ & $\begin{array}{c}40,0 \\
(5,8-92,9)\end{array}$ \\
\hline $\begin{array}{c}\text { Gleason } \\
\text { score } \leq 9, \\
\text { stage } \\
\text { T2-3N0M0 }\end{array}$ & 291 & 72 & $\begin{array}{c}41,2 \\
(25-198)\end{array}$ & $\begin{array}{c}30,3 \\
(20,1-60)\end{array}$ \\
\hline $\begin{array}{c}\text { Failure } \\
\text { after EBRT } \\
\text { and RPE }\end{array}$ & 39 & 69,5 & $\begin{array}{c}21,3 \\
(5,5-64,8)\end{array}$ & $\begin{array}{c}21,0 \\
(5,2-76)\end{array}$ \\
\hline
\end{tabular}

In the patients who underwent TURP+HIFU, the catheter was removed after a mean of 7 (3-21) days. In the patients who underwent HIFU, the catheter was removed after a mean of 14 (10-28) days. PSA values after treatment are presented in Table 2.

Table 2. PSA values during the follow-up

\begin{tabular}{|c|c|c|c|}
\hline $\begin{array}{c}\text { Group } \\
\text { description }\end{array}$ & $\begin{array}{c}\text { PSA 12 months } \\
\text { after HIFU } \\
\text { treatment, } \\
\mathrm{ng} / \mathrm{mL}\end{array}$ & $\begin{array}{c}\text { PSA 48 months } \\
\text { after HIFU } \\
\text { treatment, } \\
\mathrm{ng} / \mathrm{mL}\end{array}$ & $\begin{array}{c}\text { Recurrence 5 } \\
\text { years of } \\
\text { follow-up, \% }\end{array}$ \\
\hline $\begin{array}{c}\text { Gleason score } \\
\leq 7, \text { stage } \\
\text { T1-2N0M0 }\end{array}$ & $0,04(0-2,24)$ & $0,5(0,0-3,6)$ & 4,5 \\
\hline $\begin{array}{c}\text { Gleason score } \\
\leq 9, \text { stage } \\
\text { T2-3N0M0 }\end{array}$ & $0,05(0-48,4)$ & $3,2(0,0-21,3)$ & 25 \\
\hline $\begin{array}{c}\text { Failure after } \\
\text { EBRT and } \\
\text { RPE }\end{array}$ & $0,05(0-3,2)$ & $1,7(0,0-9,8)$ & 19,6 \\
\hline \multicolumn{2}{|c|}{}
\end{tabular}

At 12 month follow-up in the low risk group, the PSA median was $0,04(0-2,24) \mathrm{ng} / \mathrm{mL}$; in the high risk group it was $0,05(0-48,4) \mathrm{ng} / \mathrm{mL}$, with failure after EBRT and prostatectomy - $0,5(0-3,2) \mathrm{ng} / \mathrm{mL}$. At 48 months follow-up in the low risk group, PSA median was $0,5(0,0-3,6) \mathrm{ng} / \mathrm{mL}$; in the high risk group it was $3,2(0-21,3) \mathrm{ng} / \mathrm{mL}$, with failu re after EBRT and RPE - 1,7 (0-9,8) ng/mL.

During 12 months of follow-up after the treatment, we noticed the following complications: incontinence I - 17,5\%, incontinence II - 7,7\%, stricture - $18,2 \%$, fistula $-0,3 \%$. The incontinence was due to the TURP. Patients who had only HIFU did not face such problems. These complications resolved during three-six months after treatment. (Table 3).

Table 3. Complications values aft er treatment

\begin{tabular}{|c|c|c|c|c|}
\hline $\begin{array}{c}\text { Group } \\
\text { description }\end{array}$ & $\begin{array}{c}\text { Incont. } \\
\text { rate I, \% }\end{array}$ & $\begin{array}{c}\text { Incont. } \\
\text { rate II, \% }\end{array}$ & Stricture, \% & Fistula, \% \\
\hline $\begin{array}{c}\text { Gleason score } \\
\leq 7, \text { stage } \\
\text { T1-2N0M0 }\end{array}$ & 4,2 & 5,0 & 8,0 & 0 \\
\hline $\begin{array}{c}\text { Gleason score } \\
\leq 9, \text { stage } \\
\text { T2-3N0M0 }\end{array}$ & 9,0 & 6,7 & 8,7 & 0 \\
\hline $\begin{array}{c}\text { Failure after } \\
\text { EBRT and RPE }\end{array}$ & 11,2 & 5,3 & 11,0 & 0,3 \\
\hline
\end{tabular}

Six months after the treat ment prostatic volu me (measured by transrectal ultrasonography) was in average 9,3 cc (range $2-18 \mathrm{cc}$ ). It was statistically reduced in comparison with the initial volume $(\mathrm{p}<0,01)$.

HIFU is a repeatable procedure, 7 patients needed to undergo a second treatment due to a local recurrence.

$70 \%$ of the patients reported an improvement in the quality of life six months after treatment in comparis on with their quality of life six months before the treatment and $30 \%$ reported no change. These percentages are statistically significant.

Finally, we confirmed that HIFU has been generally successful in $77,0 \%$ of treated patients (182 biochemical relapses in 795 patients). The success rate was represented as follows: $95,5 \%$ in the low risk group, $75 \%$ in the high risk group, $80,4 \%$ in the group with failure after EBRT and RPE (Figure 4).

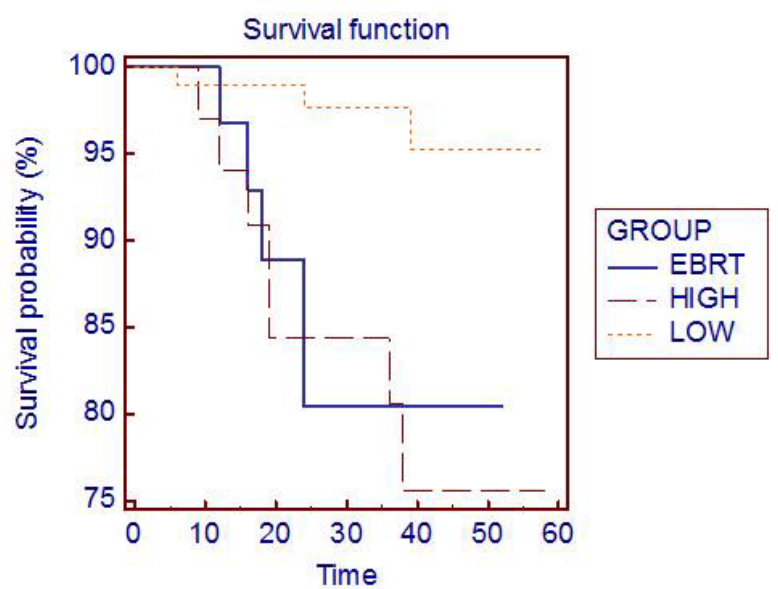

Figure 4. Kaplan-Meier disease-free survival (DFS) curves according to risk group after HIFU

\section{Discussion}

Treatment for PC may include: active surveillance, interstitial prostate brachytherapy, EBRT and RPE. There is still ongoing debate on the efficiency of focal treatment, but at the same time different focal options emerge. Brachytherapy and radiation external beam therapy are the 
most used as minimally invasive techniques, not only for the therapy of localized PC but also for the palliation of high-grade tumours. So me medical as sociations recommend HIFU for treatment of PC, but its accuracy is still not clear. Prostate cancer is dependent on the presence of androgens. Patients that are not suitable for radical surgery and with metastatic disease are typically first treated with hormonal ablation: strategies include testicular androgen deprivation by either bilateral orchidectomy or administration of a luteinizing hormone re leasing hormone (LHRH) agonist, and treatment with anti-androgens such as flutamide to compete with testosterone for the androgen receptor binding site. Unfortunately, resistance to androgen suppression invariably develops: cells accumulate further genetic abnormalities and proliferate despite low testosterone levels at a median interval of 12-16 months after initiation of endocrine treatment. Subsequent lines of hormonal therapy act through related pathways and include the use of the synthetic oestrogen, the reduction of adrenal androgen production by administration of glucocorticoids. There are limited treatment options once recurrent prostate cancer develops androgen independence. Palliative chemotherapy with docetaxel has been shown to improve survival and is commonly instituted for metastatic disease following failu re of maximal androgen blockade but is not suitable for all patients, particularly those with poor performance status. Those patients with no metastatic disease may receive local salvage treatment such as brachytherapy or HIFU.

In Russia, localized prostate cancer, when possible to conduct RPE, detected only $35 \%$ of patients[1]. In this case, among patients with stage I-II after radical prostatectomy or radiation therapy in $25-50 \%$ of cases prostate cancer recurrent is developed[32]. Therefore, patients are not suitable for surgery or radiation therapy, and with recurrent prostate cancer assigned to hormone therapy: bilateral orchiectomy or maximu m androgen blockade. It is noted that the rate of relapse-free and overall survival of patients with prostate cancer have remained unchanged for several decades (12-24 and 24-36 months respectively)[33]. The second and the third lines of hormone therapy, chemotherapy are effective only in $15-20 \%$ of cases and do not lead to a significant increase life expectancy of patients, while possessing significant side effects [4, 27, 28, 30].

It should be noted that at present tactics and strategies of prostate cancer treatment has not been developed in accordance with the implemented in the practice minimally invasive new technologies, there are no clinically based recommendations. Publications of focal prostate cancer therapy are few, they are based on small clinical material, have a short period of observation, and do not define the role and the place of HIFU-therapy in the treatment of prostate cancer. To date, long-term[31] and the medium-term results published[32, 33] about HIFU-therapy of prostate cancer. According to a European multicenter study that included 559 patients with prostate cancer in low-and moderate-risk, Thüroff et al.[30] reported a negative biopsy result after the HIFU-therapy in $87.2 \%$. Blana et al. evaluated the results of
HIFU in 146 patients with a mean follow-up of 22.5 months median preoperative PSA was $7.6 \mathrm{ng} / \mathrm{mL}$, while the median PSA level at 3 months after therapy was $0.07 \mathrm{ng} / \mathrm{mL}$ [29].

We analys ed the results of HIFU treatment of 795 patients with prostate cancer. The estimated 5-year disease-free survival Kap lan-Meer had 95.5\% effic iency of HIFU therapy in the group with low risk of progression and $75 \%$ in the group with high risk of progression. Treatment results showed that, in general HIFU-therapy was successful in $90.9 \%$ of patients. At the same time there were moderate short-term side effects. However, it was obvious that a more long-term monitoring of the effectiveness of HIFU therapy in patients with prostate cancer were necessary.

\section{Conclusions}

The most recent publications concluded that the use of HIFU is an effective standard treatment for prostate cancer with a broad range of indications in all tumour stages: in the primary treatment of local prostate cancer, in patients with local recurrence after failure of any primary treatment, and as an adjuvant therapy in the palliation of systemic prostate cancer.Our experience shows that HIFU is safe, minimally invasive, effective in treatment for localized and locally advanced prostate cancer, after EBRT and prostatectomy.

\section{REFERENCES}

[1] Jemal A. et al. "Gender Statistics". CA Cancer J. Clin, July 7, 2010.

[2] Chissov V, Starinsky V, Petrova G. "Malignant neoplasms in Russia in 2010 (morbidity and mortality)", M. FGBU "MNIOI by Herzen "Ministry of Russia", Russia, 2012.

[3] Prostate Cancer Treatment Guidelines, NCCN, v.1.2012.

[4] Tannock IF, Osoba D, Stockler MR, et al. "Chemotherapy with mitoxantrone plus prednisone or prednisone alone for symptomatic hormone-resistant prostate cancer: a Canadian randomized trial with palliative end points". J Clin Oncol, 1996, Vol.14, p.1756-64.

[5] Petry lak DP, Tangen CM, Hussain MH, et al. "Docetaxel and estramustine compared with mitoxantrone and prednisone for advanced refractory prostate cancer", N Engl J Med, 2004, Vol.351, p.1513-20.

[6] Tannock IF, de Wit R, Berry WR, et al. on behalf of the tax 327 Investigators. "Docetaxel plus prednisone or mitoxantrone plus prednisone for advanced prostate cancer", N Engl J Med, 2004, Vol.351, p.1502-12.

[7] Thuroff S, Chaussy C, Vallancien G, et al. "High-intensity focused ultrasound and localized prostate cancer: efficacy results from the European multricentric study", J Endourol, t.17 (8), p.673-7, 2003.

[8] Lynn JG, Zwemer RL, Chick AJ, Miller AE. A new method for the generation and use of focused ultrasound in experimental biology. J Gen Physiol 1942; 26: 179-193 
[9] Fry WJ, Barnard JW, Fry EJ, Krumins RF, Brennan JF. Ultrasonic lesions in the mammalian central nervous system. Science $1955 ; 122$ : 517-518

[10] Chaussy Ch., Thuroff S. "Transrectal high-intensuty focused ultrasound for local treatment of prostate cancer: current role", Arch. Esp. Urol, 2011, vol.64 (6), p. 493-506.

[11] ter Haar G "Intervention and therapy", Ultrasound Med Biol, 2000, 23 (Supp1 1), S51-S54.

[12] Chapelon JY et al. "Effects of high-energy focused ultrasound on kidney tissue in the rat and the dog", Eur Urol, 1992, vol. 22, p.147-152.

[13] Uchida $\mathrm{T}$ et al. "Transrectal high-intensity focused ultrasound for treatment of patients with stage $\mathrm{T} 1 \mathrm{~b}-2 \mathrm{n} 0 \mathrm{~m} 0$ localized prostate cancer: a prelimin ary report", Urology, 2002, vol.59, P.394-398.

[14] Chapelon JY et al. "New piezoelectric transducers for therapeutic ultrasound", Ultrasound Med Biol, 2002, vol. 26 , p.153-159.

[15] Curiel L et al. "1.5-D high intensity focused ultrasound array for non-invasive prostate cancer surgery", IEEE Trans Ultrason Ferroelectr Freq Control, 2002, vol.49, p. 231-242.

[16] Tan JS et al. "Design of focused ultrasound phased arrays for prostate treatment", Ultrasonics Symp Proc IEEE 2, 2002, p.1247-1251.

[17] Chavrier F et al. "Modeling of high intensity focused ultrasound-induced lesions in the presence of cavitation bubbles", J Acoust Soc Am, 2000, vol.108, p. 432-440.

[18] Curiel L et al. "Experimental evaluation of lesion prediction modelling in the presence of cavitation bubbles: intended for high-intensity focused ultrasound prostate treatment", Med Biol Eng Comput, 2004, vol.42, p. 44-54.

[19] Hynynen $\mathrm{K}$ et al. "A clinical, noninvasive, MR imaging-monitored ultrasound surgery method", Radiographics, 1996, vol.16, p.185-195.

[20] Wu T et al. "Assessment of thermal tissue ablation with MR elastography”, Magn Reson Med, 2001, vol.45. P.80-87.

[21] Vaezy S et al. "Real-time visualization of high-intensity focused ultrasound treatment using ultrasound imaging", Ultrasound Med Biol, 2001, vol.27, p.33-42.

[22] Sedelaar JPM et al. "The application of three-dimensional contrast-enhanced ultrasound to measure volume of affected tissue after HIFU treatment for localized prostate cancer", Eur Urol, 2000, vol.37, p.559-568.

[23] $\mathrm{Lu} \mathrm{J}$ et al. "In vitro measurement of speed of sound during coagulate tissue heating", Ultrasonics Symp Proc IEEE 2, 1996, p.1299-1302.

[24] Thüroff S et al. "High-intensity focused ultrasound and localized prostate cancer: efficacy results from the European multicentric study", J Endourol, 2003, vol.17, p.673-677.

[25] Rebillard X et al. "Treatment by HIFU of prostate cancer: survey of literature and treatment indications", Prog Urol, 2003, vol.13, p.1428-1456

[26] Djavan B., Moul J.W., Zlotta A. et al. "PSA progression following radical prostatectomy and radiation therapy: new standards in the new Millennium”, Eur Urol., vol.43, № 1, p.12-27, 2003.

[27] Hellerstedt B.A., Pienta K.J. "The current state of hormonal therapy for prostate cancer”,C.A. Cancer J. Clin., vol. 52, p.154-179, 2002.

[28] Tannock IF, Osoba D, Stockler MR, et al. "Chemotherapy with mitoxantrone plus prednisone or prednisone alone for symptomatic hormone-resistant prostate cancer: a Canadian randomized trial with palliative end points", J Clin Oncol., T.14, - p.1756-64, 1996.

[29] Petry lak DP, Tangen CM, Hussain MH, et al. "Docetaxel and estramustine compared with mitoxantrone and prednisone for advanced refractory prostate cancer", N Engl J Med., T.351, p.1513-20, 2004.

[30] Tannock IF, de Wit R, Berry WR, et al. "Docetaxel plus prednisone or mitoxantrone plus prednisone for advanced prostate cancer", N Engl J Med., T.351, p.1502-12, 2004.

[31] Blana A, MuratFJ, Walter B, Thuroff S, Wieland WF, Chaussy C, et al. "First analisys of the long-term result with High-intensity focused ultrasound with localised prostate cancer", Eur. Urol., T. 53, p. $1194-201,2008$.

[32] Uchida T, Shoji S, Nakano M, Hongo S, Nitta M, Murota A, Nagata Y. "Transrectal high-intensity focused ultrasound for the treatment of localized prostate cancer: eight-year experience”. Int J Urol., Nov. - T.16 (11), p.881-6, 2009.

[33] Gelet A, Chapelon JY, Bouvier R, Rouvie're O, Lyonnet D, Dubernard JM "Transrectal high intensity focused ultrasound for the treatment of localised prostate cancer: factors influencing the outcome”, Eur Urol., T. 40,p. 124-129, 2001. 